\title{
The ITGB3 Genevariant among Sample of Glanzmannthrombasthenia Iraqi Patients
}

\author{
Hayderkareemkataa AL-Aidy ${ }^{1}$, Ehab Dawood Salman², Safa A Faraj ${ }^{3}$, Zaid Jamal Mahmood ${ }^{4}$ \\ ${ }^{1}$ MSC Molecular Biology, Wassit Health Department, Ministry of Health, Iraq, ${ }^{2}$ Ph.D Molecular Biology \\ Department of Biotechnology, College of Science, University of Baghdad, Iraq, ${ }^{3}$ MD Pediatrics Hema-oncologist, \\ Wasit University, College of Medicine, Iraq, ${ }^{4}$ M.B.Ch.B . FIBMS, Congenital Bleeding, Children Welfare Hospital, \\ Medical City
}

\begin{abstract}
Case control study was used,with Glanzmann's thrombasthenia (GT) patients ( $\mathrm{n}=15)$ and healthy individual control $(n=20)$.

It was successfully identified three SNP in ITGB3 gene by using PCR technique and direct sequencing. The first SNP c. * 1479T> C (rs115310198) was presented with three genotypes (TT, TC and CC). The genotype frequencies of TT in control group (87.6 vs. $95 \%$ ) show non-significant difference ( $p>0.05)$ compared with GT patients . It was also noticed the frequency of mutant allele $(C)$ revealed non-significant difference $(\mathrm{p}>$ 0.05 ) in GT patients compared with controls group ( 13.3 vs. $2.5 \%$; OR $=6 ; \mathrm{EF}=0.03 ; 95 \%$ C.I. $=0.65$ to $55.05)$ that mean $(C)$ allele is risk factor associated with GT patients .

The c.*713A>G (rs2317676) was given with three genotypes (AA, AG and GG). The frequencies of these genotypes show non-significant difference $(\mathrm{p}>0.05)$ between control and GT patient, while the mutant allele $(G)$ show non-significant difference $(\mathrm{p}>0.05)$ in GT patients compared with controls group (16.6 vs. $5 \%$; $\mathrm{OR}=3.8 ; \mathrm{EF}=0.4 ; 95 \%$ C.I. $=0.70$ to 20.63$)$ and it was risk factors of patient GT. The c. ${ }^{*} 1016 \mathrm{~T}>\mathrm{A}$ (rs3809865) showed three genotypes (TT, TA and AA) with two alleles ( $T$ and $A$ ). The frequencies of these genotypes TT ( 87.6 vs. $85 \%)$, TA (6.6vs. $15 \%)$ and the third genotype AA (6.6 vs. $0 \%)$ show non-significant difference $(\mathrm{p}>0.05)$ between control and GT patient but the genotype (AA) $(\mathrm{OR}=4.24)$ was considered as risk factors with GT patients . It was also found the mutant allele $(A)$ revealed non-significant difference $(\mathrm{p}$ $>0.05)$ in GT patients compared with controls group ( 10 vs. $7.5 \%$; OR $=1.37 ; \mathrm{EF}=0.11 ; 95 \%$ C.I. $=0.26$ to 7.14). $(A)$ allele $(\mathrm{OR}=1.37)$ is positively associated with $\mathrm{GT}$ patients and negatively associated with healthy subject .
\end{abstract}

Keywords: Glanzmann'sthrombasthenia, ITGB3 Gene Polymorphisms, rs115310198,rs2317676,rs3809865.

\section{Introduction}

Glanzmann'sthrombasthenia (GT) can be inherited in an autosomal recessive manner ${ }^{(1,2)}$ or acquired as

\section{Corresponding Author:}

\section{Hayderkareemkataa AL-Aidy}

Wassit health department, Ministry of Health, Iraq MSC Molecular Biology, Wassit Health Department, Ministry of Health, Iraq, Kut, Iraq e-mail: dr.haidarkareem@gmail.com an autoimmune disorder ${ }^{(1,3)}$. GT is an abnormality of the platelets in which the platelets contain defective or low levels of integrin $\alpha_{\mathrm{IIb}} \beta_{3}$ formerly known as glycoprotein $\mathrm{IIb} / \mathrm{IIIa}(\mathrm{GpIIb} / \mathrm{IIIa})$ which is a receptor for fibrinogen. As a result, no fibrinogen bind of platelets to other platelets can occur, and the bleeding time is significantly prolonged ${ }^{(3)}$. The Clinical manifestations of GT including lifelong bleeding, menorrhagia, gastrointestinal bleeding, and easy fall injury ${ }^{(4)}$.

The prevalence of GT is markedly different among different ethnic groups, indicating that the difference in 
genetic background contributes to GT susceptibility, so recent genome-wide association studies reported strong and reproducible associations of multiple genetic variants in ITGB3([ MIM] 173470)gene with GT susceptibility (Gabriele, Canaliet al. 2019).

The ITGB3 (Integrin Subunit Beta 3) is a protein coding gene. The ITGB3 protein product is the integrin beta chain beta 3 . Integrins are integral cell-surface proteins composed of an alpha chain and a beta chain. A given chain may combine with multiple partners resulting in different integrins. Integrin beta 3 is found along with the alpha IIb chain in platelets. Integrins are known to participate in cell adhesion as well as cellsurface mediated signalling ${ }^{(5)}$.

By demonstrating the response to phorbol esters, various other factors and biological processes can regulate the expression of $\beta 3$ and control the expression of $\beta 3$ at the transcription level. ${ }^{(6)}$.Most commonly, the expression of GPIIb/IIIa on the surface of platelets is very low or absent, which is caused by mutations that lead to reduced mRNA stability or defects in posttranslational processing ${ }^{(7) .}$

The molecular and functional characterization of the mutations has provided important insights to the better understanding of the biosynthesis and structure-function relationships of the GPIIb/IIIa complex with the disease. It also adds important knowledge about the biology of other molecules of the integrin family $(8,9)$.

Genetic testing in GT patients is very important in the quality of life of the affected individuals and it facilitates prenatal diagnosis (PND) or pre-implantation genetic diagnosis (PGD) for at-risk families. The identified mutations will span the current database of the mutations of GT, so this study aimed at identifying mutations in ITGB3 gene associated with GT in sample of Iraqi patients.

\section{Materials and Method}

Subjects: Fifty two GT patients were enrolled in the case control study during the period of March 2019 - September 2020. these Patients suffering from dysfunction of platelets were taken from iraqi populations with ages range from 2 to 50 years including 30 woman and 22 man from pediatric teaching hospital in Baghdad city . Sixty healthy Iraqi population samples were collected as a control group, whose ages ranged between 3 and 50 years, including 30 woman and 30 men.
Sample Collection: From each participating subject, $5 \mathrm{ml}$ of venous blood was collected using $5 \mathrm{ml}$ disposable syringe. The blood was distributed into two aliquots. For the first, $3 \mathrm{ml}$ of blood was dispensed in plain tube, and after clotting, the tube was centrifuged (2000-3000 rpm for 20 minutes) to collect serum. The serum was distributed into aliquots in $0.5 \mathrm{ml}$ eppendorf tubes, and the tubes were used to detection of human Platelet Membrane Glycoprotein IIBIIIA (also known as GPIIb/IIIa) in serum. The remaining blood $(2 \mathrm{ml})$ was dispensed in EDTA tube, and frozen at $-20 \mathrm{C}$ until extraction of DNA for single nucleotide polymorphism (SNP) genotyping of $I T G B 3$ gene .

Measurement of Glycoprotein IIBIIIA Serum Levels: The quantitative of human Platelet Membrane Glycoprotein IIBIIIA was assessed in serum of GT patients and controls by means of ELISA (enzyme linked immunosorbent assay) principles. The assessment was carried out by using Human Platelet Membrane GPIIb/IIIa ELISA Kit that was produced by bioassay technology laboratory Company (china.), and the manufacturer instructions were followed. The sample results were calculated by interpolation from a standard curve that was performed in the same assay as that for the samples by using standard curve fitting equations for GPIIb/IIIa.

DNA isolation: Fifteen patient samples were selected based on the results of the ELISA examination and clinical signs and beside Twenty healthy individual subject were used as control group . Genomic DNA was isolated from blood sample for fifteen patient and twenty healthy subjects as control group according to the protocol of kit (ReliaPrep ${ }^{\text {TM }}$ Blood gDNAMiniprep System, Promega).

Primers and optimization of PCR reaction: Regions of ITGB3 gene were selected and amplified by PCR using primers (designed by the program PRIMER3) . PCR reaction system contained 12 $\mu \mathrm{M}$ of Master Mix, $10 \mu \mathrm{M}$ each of oligonucleotide primers, $8.5 \mu \mathrm{M}$ Nuclease Free Water, $2 \mu \mathrm{M}$ Taq DNA Polymerase. Thermocycling conditions of primers ITGB3 -(F5'-TCCATAGCACCTCCACATA-3' and R5 '-GGGTTTGGAGAGAGGATAGA-3', and primers -F5 '-TGAGCAGGTGTTCTTCATTAC-3' and -R5'CTGTGGCCTCTCAGATTAAAG-3') were as follows: an initial denaturation at $95^{\circ} \mathrm{C}$ for $5 \mathrm{~min}$, followed by 30 cycles of denaturation, annealing, and extension at $95^{\circ} \mathrm{C}$ for $45 \mathrm{~s}, 60^{\circ} \mathrm{C}$ for $45 \mathrm{~s}$, and $72{ }^{\circ} \mathrm{C}$ for $45 \mathrm{~s}$ Respectively. 
A final extension step $\left(72^{\circ} \mathrm{C}, 7 \mathrm{~min}\right)$ was performed at the end.

Direct Sequencing analysis: PCR products were directly sequenced using by Macrogen Corporation of Korea, and the results were analyzed using a genious program. according to the manufacturer's protocol. The samples were then run on the ABI3730XL genetic analyzer (TF). The sequence is compared with the cDNA sequence of the human genome and gene, and its accession number is ITGB3 (NM:000212, NC:000017).

Statistical analysis: Allele frequencies of ITGB3 gene and significant departure from Hardy-Weinberg (H-W) equilibrium were calculated using H-W calculator for two alleles, which is available free online at (https://wpcalc.com/en/equilibrium-hardy-weinberg/) . A Significant differences between the observed and expected frequencies were assessed by Pearson's Chisquare test (10). Alleles and genotypes of SNPs of ITGB3 gene were presented as percentage frequencies, and significant differences between their distributions in GT patients and controls were assessed by two-tailed Fisher's exact probability (P). In addition, odd ratio (OR), etiological fraction (EF) and preventive fraction (PF) were also estimated to define the association between SNPs GPIIb/IIIa alleles and genotypes with the disease, and these estimations were calculated by using the WINPEPI computer programs for epidemiologists ${ }^{(11)}$.

\section{Result}

Form total of fifty-two patient with dysfunction of platelets ELISA test show fifteen patients with GT disease.

The product of PCR amplification was showed after staining with ethidium bromide, Where a main band (904bp in length) appeared on the gel, representing the amplification of the restriction region of the ITGB3 gene from chr17: 47310522-47311425, and the amplification between chr17: 47311191-47312137 was showed a region which represented (947bp) on the gel (Figure 1).

The direct DNA sequencing result reveald three mutations were found $\left(\mathrm{c} .{ }^{*} 1479 \mathrm{~T}>\mathrm{C}, \mathrm{c} . * 713 \mathrm{~A}>\mathrm{G}\right.$, and c. $\left.{ }^{*} 1016 \mathrm{~T}>\mathrm{A}\right)$ of an ITGB3 gene .
The c. * 1479T> C (rs115310198) mutation, replace the nucleotide $T$ at chr17:47311683 (GRCh38. p12) with $C$, which is located in the 3'UTR region of the integrin $\beta 3$ gene(figure 2). The genotyping of c. ${ }^{*} 713 \mathrm{~A}>\mathrm{G}(\mathrm{rs} 2317676)$ changed $\mathrm{A}>\mathrm{G}$ in three samples (one homozygotes and two heterozygotes) of ITGB3 gene chr17:47310917 (GRCh38.p12) show in (figure 3) . c. ${ }^{* 1016 T}>A(r s 3809865)$ is located in the 3 'UTR region of the $I T G \beta 3$ gene, and $\mathrm{T}>\mathrm{A}$ changes at position chr17:47311220 (GRCh38.p12) (figure 4) .

The genotype distribution of these three variants is consistent with Hardy-Weinberg balance $(\mathrm{P}>0.05)$. The SNP c.*1016T $>$ A (rs3809865) at positionchr17:47311220 (GRCh38.p12) was presented with two alleles ( $T$ and $A$ ) and three genotypes (TT, TA and AA). These genotypes showed deviation from HWE in GT patientsand control group respectively, because there was a significant difference between the observed and expected genotype frequencies $(\mathrm{p} \leq 0.05)$. Comparing GT patients to controls revealed that genotype frequencies of TT (87.6 vs. $85 \%$ ) and TA (6.6vs. 15\%), while the third genotype (AA) was observed with a frequency 6.6 vs. $0 \%$ in patients and control group respectively, The genotypes AA,AT and TT in control group was non-significant difference $(\mathrm{P}>0.05)$ compared to $\mathrm{GT}$ patient but the genotype (AA) $(\mathrm{OR}=4.24)$ was considered as risk factors with GT patients .It was also noticed the frequency of mutant allele $(A)$ show a nonsignificant difference $(\mathrm{p}>0.05)$ in GT patients compared to controls ( 10 vs. $7.5 \%$; OR $=1.37 ; \mathrm{EF}=0.11 ; 95 \%$ C.I. $=0.26$ to 7.14$)$ that mean $(A)$ allele $(\mathrm{OR}=1.37)$ is positively associated with GT patients and negatively associated with healthy subject, while in the control group the frequency of $(T)$ allele show a non-significant difference ( $p>0.05$ ) compared to GT patients (90 vs. 92.5\%; reciprocal $\mathrm{OR}=1.37 ; \mathrm{EF}=0.71 ; 95 \%$ C.I. $=$ 0.14 to 3.80$)$. In this case the $(T)$ allele associated with healthy subject, but in GT patients group was negatively associated with reciprocal $\mathrm{OR}=1.37$ (Table). 
$-A-$

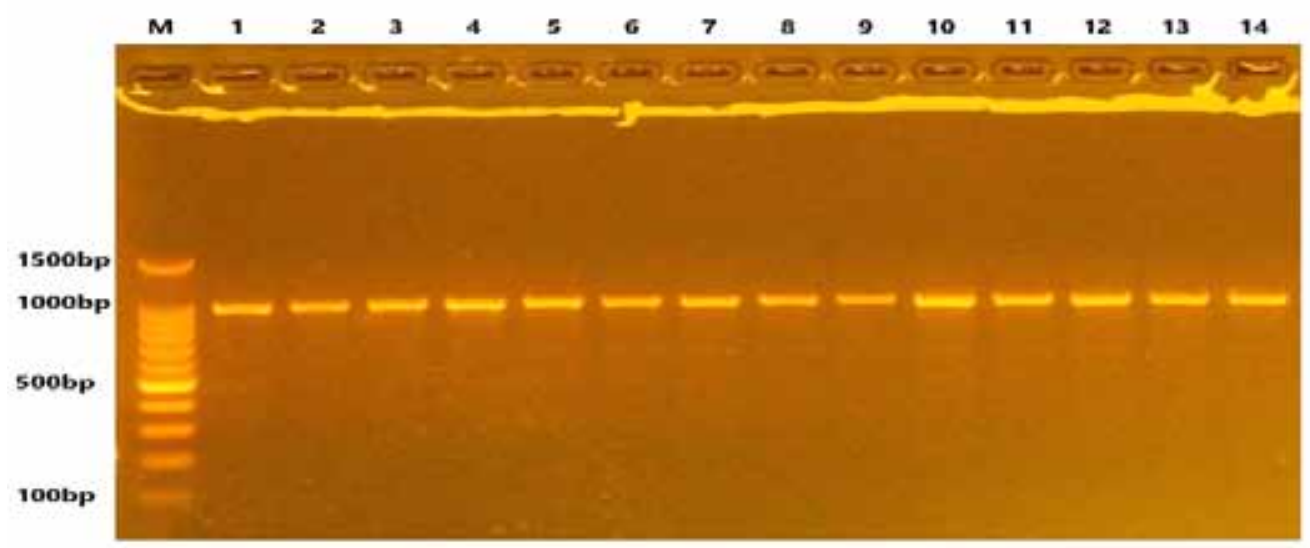

-B-

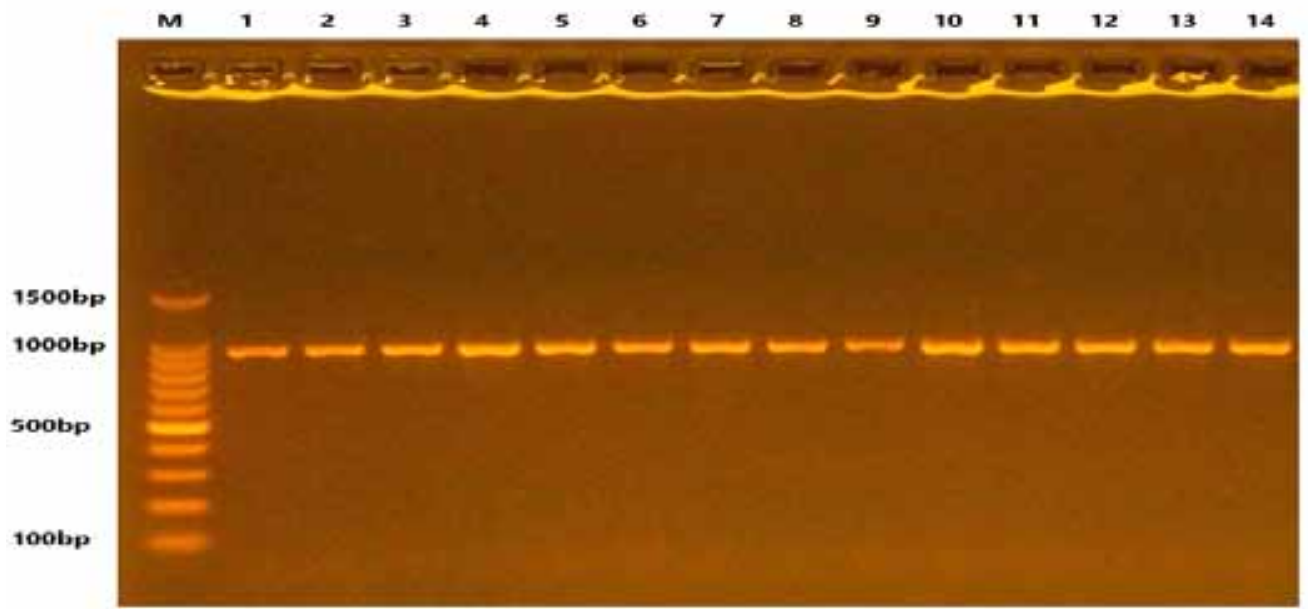

Figure 1: The amplicon for ITGB3 gene : A- from chr17 :47310522-47311425 which contains part from 3'UTR of GT patients with band have 904 bp . B- from chr17: $47311191-47312137$ which contains part from 3 UTR of GT patients with band have $947 \mathrm{bp}$. The $2 \%$ agarose gel was assay by using at $7 \mathrm{C}$ voltages for one hour

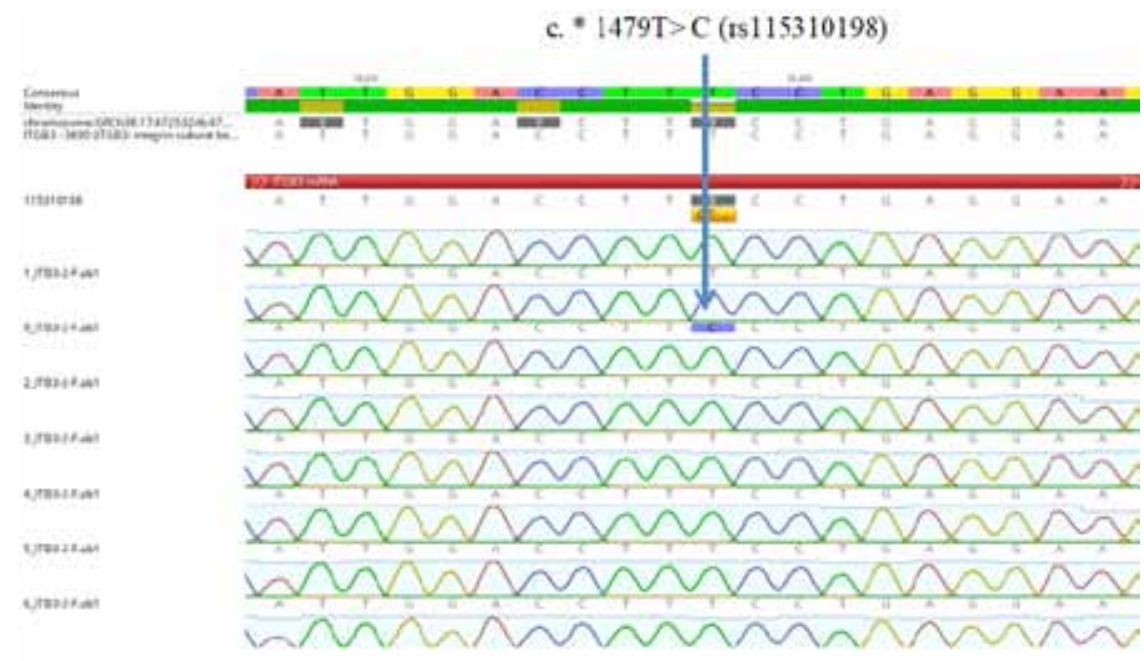

Figure 2 : The DNA direct sequencing for GT patients show the nucleotide substation $T>C$ at position 1479 in $3 U T R$ region for $\pi G B 3$ gene . 


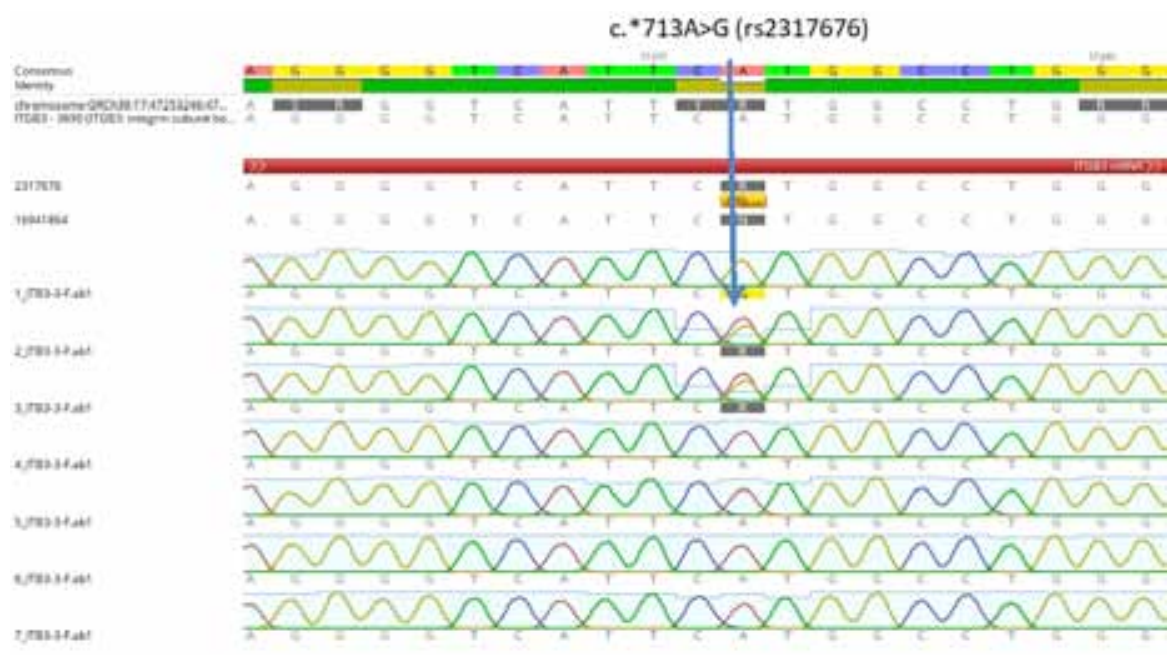

Figure 3 : The DNA direct sequencing for GT patients show the nucleotide substation $A>G$ at position 713 in $3 U T R$ region for $I T G B 3$ gene.

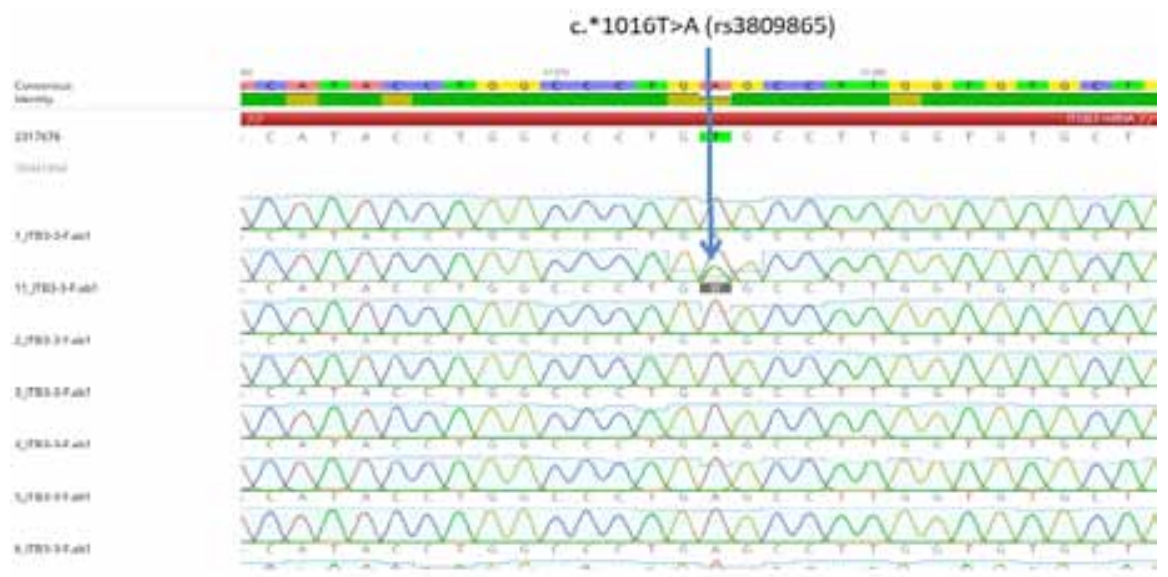

Figure 4: The DNA direct sequencing for GT patients show the nucleotide substation $T>A$ at positior 1016 in 3UTR region for $1 T$ GB3 gene .

The SNP rs2317676 (c. $\left.{ }^{*} 713 \mathrm{~A}>\mathrm{G}\right)$ at a place: 47310917 for chromosome (GRCh38.p12) was presented with two alleles $(A$ and $G$ ) and three genotypes (AA, AG and GG). These genotypes showed deviation from HWE in GT patients, because there was a significant difference between the observed and expected genotype frequencies ( $\mathrm{p} \leq 0.05)$, it was also noticed the genotypes frequencies (AA, AG and $G G$ ) show deviation from HWE in controls group with significant difference $(\mathrm{p} \leq$ 0.05). Comparingcontrols to GT patients revealed that genotype frequencies of AA (80.6vs. 90\%), AG (6.6vs. $5 \%$ ), and The third genotype (GG) $13.3 \mathrm{vs}$. $0 \%$. These genotypes were non-significant difference $(\mathrm{P}>0.05)$ compared between control and GT patient. it was also noticed the frequency of mutant allele $(G)$ show nonsignificant difference $(\mathrm{p}>0.05)$ in GT patients compared with controls $(16.6$ vs. $5 \%$; OR $=3.8 ; \mathrm{EF}=0.4 ; 95 \%$
C.I. $=0.70$ to 20.63 ), while in the control group the frequency of $(A)$ allele show a non- significant difference ( $\mathrm{p}>0.05)$ compared to GT patients (83.3 vs. $95 \%$; EF $0.71 ; 95 \%$ C.I. 0.05 to 1.43$)$. In this case the $(A)$ allele associated with healthy subject and non-associated with GT patients(reciprocal OR $=3.8$ )and considered as protective factor (Table).

The rs115310198 at position 47311683 for chromosome 17(GRCh38.p12) was presented with three genotypes (TT, TC and CC), and two alleles ( $T$ and $C)$.These genotypes showed deviation from HWE in GT patients, because there was a significant difference between the observed and expected genotype frequencies $(\mathrm{p} \leq 0.001)$, it was also noticed a deviation from HWE in controls treatment with non-significant difference $(p>$ 0.05). Comparing controls to GT patients revealed that 
genotype frequencies of TT (87.6 vs. $95 \%)$, TC (0 vs. $5 \%$ ), and The third genotype (CC) 13.3 vs. $0 \%$. The $\mathrm{TT}$, TC, and CC genotypes were show non-significant difference $(\mathrm{p}>0.05)$ between healthy subject and GT patient . The $\mathrm{CC}$ genotype $(\mathrm{OR}=7.5)$ was considered as risk factors . it was also noticed the frequency of mutant allele $(C)$ show non- significant difference $(p>0.05)$ in GT patients compared to controls (13.3 vs. 2.5\%; OR $=6 ; \mathrm{EF}=0.03 ; 95 \%$ C.I. $=0.65$ to 55.05$)$ that mean
(C) allele is risk factor associated with GT patients and negatively associated of healthy, while in the control group the frequency of $(T)$ allele show non-significant difference ( $p>0.05$ ) compared to GT patients (86.6 vs. $97.5 ; \mathrm{OR}=0.17$; EF $0.37 ; 95 \%$ C.I. $=0.02$ to 1.53 ) and it $(\mathrm{OR}=6$ reciprocal) was considered as protective factor of health subject (positively associated of health and negatively associated of GT patients) (Table).

Table : Genotype and allele frequencies and epidemiological parameters for Iraqi GT patients and controls.

\begin{tabular}{|c|c|c|c|c|c|c|c|c|c|c|c|}
\hline ITGB 3 gene & \multicolumn{3}{|c|}{ GT patients(n=15) } & \multicolumn{3}{|c|}{ Control( $(n=20)$} & \multicolumn{5}{|c|}{ Epidemiological parameters } \\
\hline SNPs & $\begin{array}{l}\text { Observed } \\
\mathrm{N}(\%)\end{array}$ & $\begin{array}{l}\text { Expected } \\
\mathrm{N}(\%)\end{array}$ & \begin{tabular}{|l}
$\mathrm{HWE}$ \\
$p$-value \\
$=0.05$
\end{tabular} & $\begin{array}{l}\text { Observed } \\
\mathrm{N}(\%)\end{array}$ & $\begin{array}{l}\text { Expected } \\
\mathrm{N}(\%)\end{array}$ & $\begin{array}{l}\text { HWE } \\
\text { p-value } \\
=0.05\end{array}$ & OR & $\mathrm{EF}$ & $\mathrm{PF}$ & $\begin{array}{l}\chi^{2} \\
p \text {-value }\end{array}$ & CI $95 \%$ \\
\hline \multicolumn{12}{|l|}{ rs 3809865} \\
\hline TT & $13(87.6)$ & $12.1(81)$ & \multirow{5}{*}{0.05} & $17(85)$ & $17.1(85.5)$ & \multirow{5}{*}{0.05} & 1.15 & 0.78 & 0.11 & 1 & $\begin{array}{l}0.18 \text { to } \\
7.45\end{array}$ \\
\hline TA & $1(6.6)$ & $2.7(18)$ & & $3(15)$ & $2.7(13.8)$ & & 0.4 & 0.12 & 0.08 & 0.6 & $\begin{array}{l}0.04 \text { to } \\
4.02\end{array}$ \\
\hline AA & $1(6.6)$ & $0.15(1)$ & & $0(0)$ & $0.11(0.5) ?$ & & 4.24 & 0.09 & 0.07 & 0.4 & $\begin{array}{l}0.18 \text { to } \\
102.5 \\
\end{array}$ \\
\hline $\mathrm{T}$ & $27(90)$ & & & $37(92.5)$ & & & $1.37^{*}$ & 0.71 & 0.25 & 1 & $\begin{array}{l}0.14 \text { to } \\
3.80\end{array}$ \\
\hline A & $3(10)$ & & & $3(7.5)$ & & & 1.37 & 0.11 & 0.02 & 1 & $\begin{array}{l}0.26 \text { to } \\
7.14\end{array}$ \\
\hline \multicolumn{12}{|l|}{ rs 2317676} \\
\hline AA & $12(80)$ & $10.4(69.4)$ & \multirow{5}{*}{0.05} & $18(90)$ & 19(95.) & \multirow{5}{*}{0.05} & 0.44 & 0.61 & 0.5 & 0.6 & $\begin{array}{l}0.07 \text { to } \\
2.90\end{array}$ \\
\hline $\mathrm{AG}$ & $1(6.6)$ & $4.16(27.7)$ & & $2(5)$ & $0.9(4.8)$ & & 0.64 & 0.15 & 0.03 & 1 & $\begin{array}{l}0.06 \text { to } \\
7.25\end{array}$ \\
\hline GG & $2(13.3)$ & $0.41(2.7)$ & & $0(0)$ & $0.1(0.6) ?$ & & 7.59 & 0.07 & 0.13 & 0.1 & $\begin{array}{l}0.37 \text { to } \\
157.72\end{array}$ \\
\hline $\bar{A}$ & $25(83.3)$ & & & $38(95)$ & & & $3.8^{*}$ & 0.3 & 0.7 & 0.13 & $\begin{array}{l}0.05 \text { to } \\
1.43\end{array}$ \\
\hline G & $5(16.6)$ & & & $2(5)$ & & & 3.8 & 0.4 & 0.12 & 0.13 & $\begin{array}{l}0.70 \text { to } \\
20.63\end{array}$ \\
\hline \multicolumn{12}{|l|}{ rs115310198 } \\
\hline TT & $13(87.6)$ & $11.2(75.1)$ & \multirow{5}{*}{0.001} & 19. (95) & $19(95)$ & \multirow{5}{*}{ N.S. } & 0.34 & 0.73 & 0.62 & 0.5 & $\begin{array}{l}0.03 \text { to } \\
3.89\end{array}$ \\
\hline $\mathrm{TC}$ & $0(0)$ & $3.4(23.1)$ & & $1(5)$ & $0.9(4.8)$ & & 0.42 & 0.1 & 0.04 & 1 & $\begin{array}{l}0.02 \text { to } \\
10.00\end{array}$ \\
\hline $\mathrm{CC}$ & $2(13.3)$ & $0.26(1.7)$ & & $0(0)$ & $0.01(0.06)$ & & 7.5 & 0.07 & 0.13 & 0.1 & $\begin{array}{l}0.37 \text { to } \\
157.72\end{array}$ \\
\hline $\mathrm{T}$ & $26(86.6)$ & & & $39(97.5)$ & & & 6* & 0.37 & 0.81 & 0.1 & $\begin{array}{l}0.02 \text { to } \\
1.53\end{array}$ \\
\hline $\mathrm{C}$ & & & & $1(2.5)$ & & & 6 & 0.03 & 0.11 & 0.1 & $\begin{array}{l}0.65 \text { to } \\
55.05\end{array}$ \\
\hline
\end{tabular}

EF: Etiological fraction, PF: Preventive Fraction, OR :Odd ratio, C.I. : Confidence interval ,HWE :Hardy-Weinberg Equilibrium , ${ }^{*}$ : odds ratio (Reciprocal), N.S non-significant . $\chi^{2} p$-value: Fishers Exact probability .

\section{Desiccation}

Glanzmann'sthrombasthenia laboratory diagnosis depends on a series of studies on platelet aggregation, molecular biology, elisa, and flow cytometry ${ }^{(4)}$.

In this study, the ELISA technique was used to differentiate between Glanzmann's patients and other patients with platelet dysfunction based on a comparison with the control group.

The use of ELISA technology can identify platelet diseases by determining the amount of reaction between 
the antigen and the receptor, so that it is possible to diagnose the presence of platelet dysfunction and the severity of the disease. the receptor GPIIb/IIIa on the platelets act as the target antigen. The use of ELISA technique for detection of cases in GT and also which is effective cost, easy, sensitive, and specific perform diagnosis ${ }^{(4)}$

$$
\text { c. }{ }^{*} 1016 \mathrm{~T}>\mathrm{A} \text { (rs3809865) and c. * 1479T }>\mathrm{C}
$$
(rs115310198) are located in the 3'UTR region of the $I T G \beta 3$ gene. The 3'UTR region regulates the expression and regulation of $\beta 3$ integrin gene at the mRNA level, and interacts with miRNA (1). rs3809865 and rs115310198 may functionally affect the binding of miRNA, therefore, the protein expression level of integrin $\beta 3$ subunit ${ }^{(12)(13)}$.

c. ${ }^{*} 713 \mathrm{~A}>\mathrm{G}(\mathrm{rs} 2317676)$ is located in the $3^{\prime} \mathrm{UTR}$ region of the $I T G \beta 3$ gene. SNP can affect the expression of integrin by affecting the stability of microRNA. (MiRNA) and gene binding, this is the mechanism proposed by rs $2317676(\mathrm{~A} / \mathrm{G})$ for the ITGB3miRNA binding site, which can affect the residual amount of a IIbb3 in the presence of other causal mutations, but this remains to be proven in $\mathrm{GT}^{(14)}$.

Conflict of Interest: There is no conflict of interest among the authors.

\section{Funding: Self}

Ethical Clearance: This study is ethically approved by the Institutional ethical Committee.

\section{Reference}

1. Kaushansky K, Lichtman MA, Beutler E, Kipps TJ, Seligsohn U, Prchal JT. Williams hematology. 8 ed: McGraw-Hill; 2010.

2. Seligsohn U. Glanzmann Thrombasthenia: A model disease which paved the way to powerful therapeutic agents. Pathophysiology of haemostasis and thrombosis. 2002;32:216-7.

3. Tholouli E, Hay CR, O'Gorman P, Makris M. Acquired Glanzmann's thrombasthenia without thrombocytopenia: a severe acquired autoimmune bleeding disorder. Br J Haematol. 2004; 127(2):20913.

4. Lobo V, Shetty S, Kulkarni B, Ghosh K. A novel ELISA for diagnosis of Glanzmann's thrombasthenia and the heterozygote carriers. Annals of hematology. 2012;91(6):917-21.
5. Bennett JS. Structure and function of the platelet integrin alpha IIbbeta3. J Clin Invest. 2005;115(12):3363-9.

6. Jin Y, Wilhide CC, Dang C, Li L, Li S-X, VillaGarcia $\mathrm{M}$, et al. Human integrin $\beta 3$ gene expression: evidence for a megakaryocytic cell-specific cisacting element. Blood, The Journal of the American Society of Hematology. 1998;92(8):2777-90.

7. Jayo A, Conde I, Lastres P, Martínez C, Rivera J, Vicente $\mathrm{V}$, et al. L718P mutation in the membraneproximal cytoplasmic tail of beta 3 promotes abnormal alpha IIb beta 3 clustering and lipid microdomain coalescence, and associates with a thrombasthenia-like phenotype. Haematologica. 2010;95(7):1158-66.

8. Motlagh F, Fallah M-S, Bagherian H, Shirzadeh T, Ghasri S, Dabbagh S, et al. Molecular genetic diagnosis of Glanzmann syndrome in Iranian population; Reporting novel and recurrent mutations. Orphanet Journal of Rare Diseases. 2019;14.

9. Bellucci S, Caen J. Molecular basis of Glanzmann's Thrombasthenia and current strategies in treatment. Blood reviews. 2002;16(3):193-202.

10. Ad'Hiah AH. Immunogenetic studies in selected human diseases: University of Newcastle upon Tyne; 1990.

11. Abramson JH. WINPEPI updated: computer programs for epidemiologists, and their teaching potential. Epidemiologic perspectives \& innovations: EP+I. 2011;8(1):1.

12. Bianconi D, Schuler A, Pausz C, Geroldinger A, Kaider A, Lenz H-J, et al. Integrin beta-3 genetic variants and risk of venous thromboembolism in colorectal cancer patients. Thrombosis Research. 2015;136(5):865-9.

13. Müller $D$, Bosserhoff $A$. Integrin $\beta 3$ expression is regulated by let-7a miRNA in malignant melanoma. Oncogene. 2008;27(52):6698-706.

14. Pillois $X$, Nurden AT. Linkage disequilibrium amongst ITGA2B and ITGB3 gene variants in patients with Glanzmann thrombasthenia confirms that most disease-causing mutations are recent. British journal of haematology. 2016;175(4):68695. 